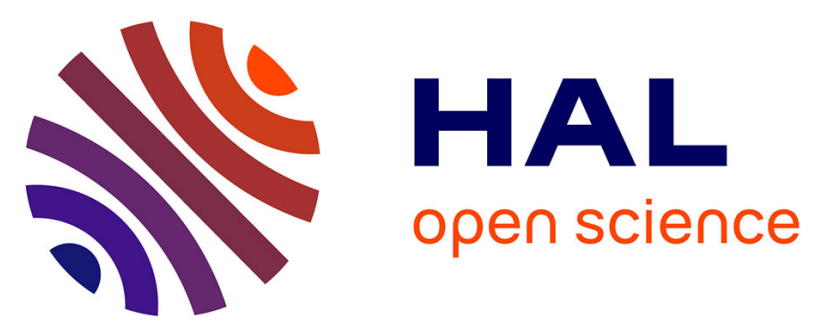

\title{
Liposomal amphotericin B pharmacokinetics in a patient treated with extracorporeal membrane oxygenation
} J B Foulquier, P Berneau, A Frérou, M C Verdier, F Saint-Marcoux, A Petitcollin, C Tron, E Bellissant, F Lemaitre

\section{- To cite this version:}

J B Foulquier, P Berneau, A Frérou, M C Verdier, F Saint-Marcoux, et al.. Liposomal amphotericin $\mathrm{B}$ pharmacokinetics in a patient treated with extracorporeal membrane oxygenation. Médecine et Maladies Infectieuses, 2019, 49 (1), pp.69-71. 10.1016/j.medmal.2018.10.011 . hal-01975936

\author{
HAL Id: hal-01975936 \\ https://hal-univ-rennes1.archives-ouvertes.fr/hal-01975936
}

Submitted on 22 Oct 2021

HAL is a multi-disciplinary open access archive for the deposit and dissemination of scientific research documents, whether they are published or not. The documents may come from teaching and research institutions in France or abroad, or from public or private research centers.
L'archive ouverte pluridisciplinaire HAL, est destinée au dépôt et à la diffusion de documents scientifiques de niveau recherche, publiés ou non, émanant des établissements d'enseignement et de recherche français ou étrangers, des laboratoires publics ou privés.

\section{(ㄷ)(1) $\$$}

Distributed under a Creative Commons Attribution - NonCommerciall 4.0 International 
Version of Record: https://www.sciencedirect.com/science/article/pii/S0399077X18306127

Manuscript_da5d6f9c6d7563561143066a207b426a

\section{Pharmacocinétique de l’amphotéricine B liposomale chez un patient sous oxygénation \\ extracorporelle}

Liposomal amphotericin B pharmacokinetics in a patient treated with extracorporeal membrane oxygenation

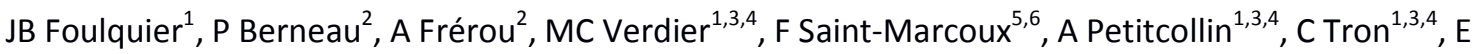
Bellissant $^{1,3,4}$, F Lemaitre ${ }^{1,3,4}$
}

${ }^{1}$ Service de Pharmacologie, Hôpital de Pontchaillou, CHU de Rennes, Rennes, France ; ${ }^{2}$ Service de Maladies Infectieuses et Réanimation Médicale, Hôpital de Pontchaillou, CHU de Rennes, Rennes, France ; ${ }^{3}$ Laboratoire de Pharmacologie Expérimentale et Clinique, Faculté de Médecine, Université de Rennes 1, Rennes, France ; ${ }^{4}$ Centre d'Investigation Clinique, CIC INSERM 1414, CHU de Rennes, Rennes, France ; ${ }^{5}$ Service de Pharmacologie, Toxicologie et Pharmacovigilance, CHU de Limoges, Limoges, France ; ${ }^{6}$ UMR INSERM 850, Université de Limoges, Limoges, France

Corresponding author: Dr Florian Lemaitre, Service de Pharmacologie, Hôpital de Pontchaillou, CHU de Rennes, 35033 Rennes cedex, France ; mail: florian.lemaitre@chu-rennes.fr

Mots clés : amphotéricine B, oxygénation par membrane extracorporelle, pharmacocinétique Keywords: amphotericin B, extracorporeal membrane oxygenation, pharmacokinetics 


\section{Introduction}

Amphotericin B is a macrocyclic polyene with a broad-spectrum antifungal activity indicated in the management of invasive fungal infections and leishmaniasis. Lipid formulations were developed to improve drug tolerability. The recommended regimen for liposomal amphotericin B in invasive pulmonary aspergillosis is $3-5 \mathrm{mg} / \mathrm{kg}$ daily infused over $30-60$ minutes.

Extracorporeal membrane oxygenation (ECMO) is a complex life-support technique which aims to compensate cardiac and/or respiratory function in case of organ failure. Its potential for interacting with the pharmacokinetics of several drugs used in the intensive care unit (ICU) is well documented. Drug sequestrations within ECMO components, as well as release from binding sites and increase in drug clearance or volume of distribution have been reported [1]. Liposomal amphotericin B may interact with ECMO device due to its physicochemical properties, but limited data is available on this subject.

\section{Patient and methods}

We report the case of a 33-year-old woman admitted to our ICU for acute respiratory distress syndrome in April 2017 (day 0). The patient had a history of Hodgkin lymphoma diagnosed in 2008, which required hematopoietic stem cell transplantation and intensive chemotherapy in April 2017. Two weeks before ICU admission, the patient presented with cough associated with chest pain and dyspnea initially treated with amoxicillin. Despite antibacterial treatment, her status worsened, and she was admitted to the ICU. On day 1 Aspergillus fumigatus, Streptococcus pneumonia, and Moraxella catarrhalis were isolated from bronchoalveolar lavage (BAL) culture. Voriconazole and piperacillintazobactam were initiated. Invasive pulmonary aspergillosis diagnosis was confirmed by chest imaging and elevated galactomannan antigen in BAL initially at 1.956 (threshold <0.5). Minimum inhibitory concentrations for voriconazole, micafungin, and amphotericin B were $0.19,0.012$, and $0.38 \mu \mathrm{g} / \mathrm{mL}$. On day 16 hemiplegia associated with microbiological failure (galactomannan antigen >6 in BAL and positive culture) led to the addition of micafungin. Respiratory symptom worsening on day 34 led to 
switching to liposomal amphotericin B (4 mg/kg/day, 6-hour infusion). Veno-venous ECMO was required while culture and antigen for Aspergillus fumigatus were still positive. Due to the complexity of the situation, a complete pharmacokinetic profile of amphotericin B was assessed at steady state on day 47 to guide therapy. Despite antifungal therapy, the patient's clinical condition continued to worsen until death on day 55.

Blood samples were collected before infusion and 2, 4, 6, 8, 16, and 20 hours after drug infusion. Drug levels were determined using liquid chromatography paired with a photodiode array detector. Pharmacokinetic parameters were estimated using a non-compartmental analysis with the PKSolver software [2].

\section{Results and discussion}

Despite the non-linear kinetic of liposomal amphotericin B, the pharmacokinetic parameters obtained in our case patient were similar to those reported in critically ill non-ECMO patients [3] (Table 1). As previously published, the use of ECMO may significantly alter pharmacokinetic profiles of commonly used drugs. Physiological changes such as a larger volume of distribution or a prolonged elimination have been reported $[4,5]$. The increase in volume of distribution is usually related to a dilutional effect associated with a loss of drug in the membrane oxygenator or polyvinylchloride tubing. Due to its molecular size and lipophilicity, liposomal amphotericin B is expected to be absorbed or sequestrated by circuit component. However, the volume of distribution calculated for our patient was similar to values observed in critically ill patients without ECMO [3]. This result also depends on the severity of the patient's underlying illness which could explain the difference with neutropenic patients and healthy volunteers $[6,7]$. The elimination of the drug can also be prolonged in case of organ failure and increase in volume of distribution. In the present case, the drug elimination was comparable to critically ill patients and longer than in the two other groups of patients (i.e., neutropenic patients and healthy volunteers) $[3,6,7]$. Hence, the ECMO device did not seem to alter the clearance of liposomal amphotericin B. Furthermore, the exposure (i.e., the area under the curve [AUC]) was, in the present 
case, closer to the value reported in ICU patients and healthy volunteers than in neutropenic patients (133, 171, 171 versus $555 \mu \mathrm{g} . \mathrm{h} / \mathrm{mL}$, respectively). Moreover, the trough concentration measured 20 hours after the onset of infusion was $4.9 \mu \mathrm{g} / \mathrm{mL}$, a result close to a very similar case where liposomal amphotericin B measured at $\mathrm{H} 13$ and $\mathrm{H} 18$ was respectively 5.8 and $6.2 \mu \mathrm{g} / \mathrm{mL}$ [8]. On the contrary, the $\mathrm{C}_{\max }$ measured in our patient was lower than that described in critically ill non-ECMO patients (8.7 versus $14.4 \mu \mathrm{g} / \mathrm{mL}$ ). This may result from the extended infusion duration performed in our patient. Extending infusion duration, which aimed to decrease renal toxicity, could have decreased treatment efficacy due to the concentration-dependent antifungal activity of amphotericin B. These findings might be in favor of a minor impact of ECMO on liposomal amphotericin B pharmacokinetics.

\section{Conclusion}

We presented the first case of a complete pharmacokinetic profile of amphotericin B in a patient treated with ECMO. ECMO did not seem to have modified the pharmacokinetics of amphotericin B suggesting that no dose adjustment should be necessary in similar patients. However, further studies are warranted to confirm this observation.

\section{Declaration of interest}

The authors declare no competing interest.

\section{Contribution of authors}

$\mathrm{JBF}, \mathrm{MCV}$, and $\mathrm{CT}$ collected the data and wrote the article.

$\mathrm{PB}$ and $\mathrm{AF}$ ensured the clinical management of the patient.

AP performed the pharmacokinetic analysis.

EB and FL supervised the work, wrote and approved the article. 


\section{References}

1. Shekar K, Fraser JF, Smith MT, et al. Pharmacokinetic changes in patients receiving extracorporeal membrane oxygenation. J Crit Care. 2012; 27:741.

2. Zhang $\mathrm{Y}$, Huo $\mathrm{M}$, Zhou J, et al. PKSolver: An add-in program for pharmacokinetic and pharmacodynamic data analysis in microsoft excel. Computer Methods Programs Biomed 2010; 99(3):306-14.

3. Heinemann $V$, Bosse $D$, Jehn $U$, et al. Pharmacokinetics of liposomal amphotericin $B$ (Ambisome) in critically ill patients. Antimicrob Agents Chemother 1997; 41:1275-80.

4. Touchard C, Aubry A, Eloy P, et al. Predictors of insufficient peak amikacin concentration in critically ill patients on extracorporeal membrane oxygenation. Crit Care 2018; 22:199.

5. Lemaitre F, Luyt CE, Roullet-Renoleau F, et al. Impact of extracorporeal membrane oxygenation and continuous venovenous hemodiafiltration on the pharmacokinetics of oseltamivir carboxylate in critically ill patients with pandemic (H1N1) influenza. Ther Drug Monit 2012; 34:171-5.

6. Coukell AJ, Brogden RN. Liposomal amphotericin B. Drugs 1998; 55:585-612.

7. Bekersky I, Fielding RM, Dressler DE, et al. Pharmacokinetics, excretion, and mass balance of liposomal amphotericin B (AmBisome) and amphotericin B deoxycholate in humans. Antimicrob Agents Chemother 2002; 46:828-33.

8. Ruiz S, Papy E, Da Silva D, et al. Potential voriconazole and caspofungin sequestration during extracorporeal membrane oxygenation. Intensive Care Med 2009; 35:183. 
Tableau 1. Paramètres pharmacocinétiques de l'amphotéricine B liposomale chez des patients sous ECMO versus sans ECMO.

Table 1. Pharmacokinetic parameters of liposomal amphotericin B in patients with ECMO vs nonECMO patients.

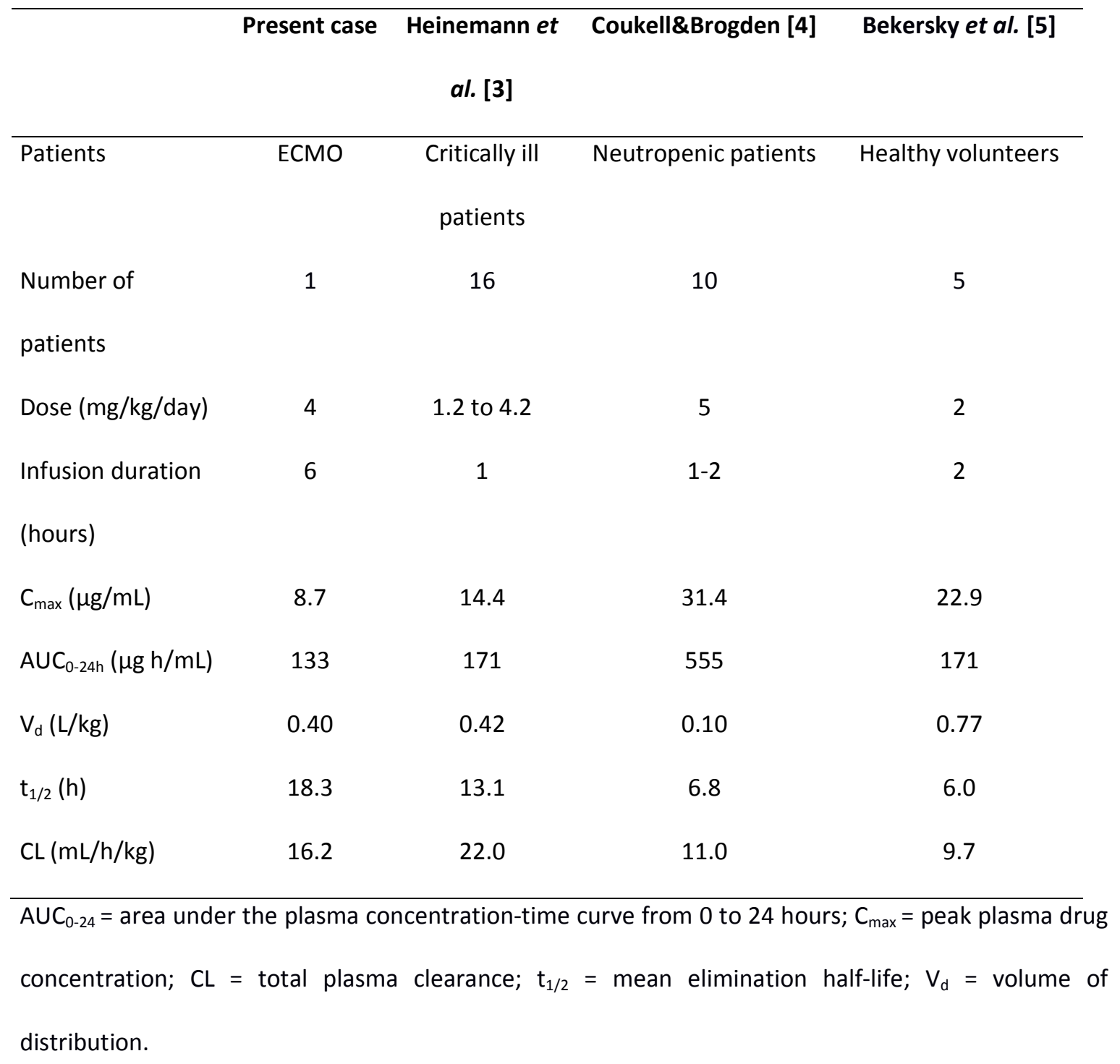

